\title{
ПАЛИНОЛОГИЧЕСКИЕ ИССЛЕДОВАНИЯ ВАЛДАЙСКИХ ОТЛОЖЕНИЙ РАЗРЕЗОВ ДРИЧАЛУКИ И КАСПЛЯНЕ В СЕВЕРО-ВОСТОЧНОЙ БЕЛОРУССИИ
}

Отложения позднего плейстоцена широко распространены в СевероВосточной Белоруссии. Особое вңимание привлекает ряд разрезов на береговых обрывах Западной Двины и ее притоков, вскрывающих отложения времени максимальной стадии валдайского оледенения и предшествующие ей слои в окрестности г. Сураж Витебской областй. Краевые образования этой стадии расположены южнее и считаются возникшими около 20000 лет назад (Палеогеография Европы..., 1982). Белорусскими исследователями вложен большой труд в изучение этого района как в общегеологическом, так и в палеоботаническом и физикохимическом аспектах (Арсланов и др., 1971 $а$, 1973; Махнач, 1971; Назаров, 1979; Санько, 1982 и др.). Большинство исследователей признает существование перигляциальных условий до распространения максимальной стадии валдайского оледенения, но некоторые допускают

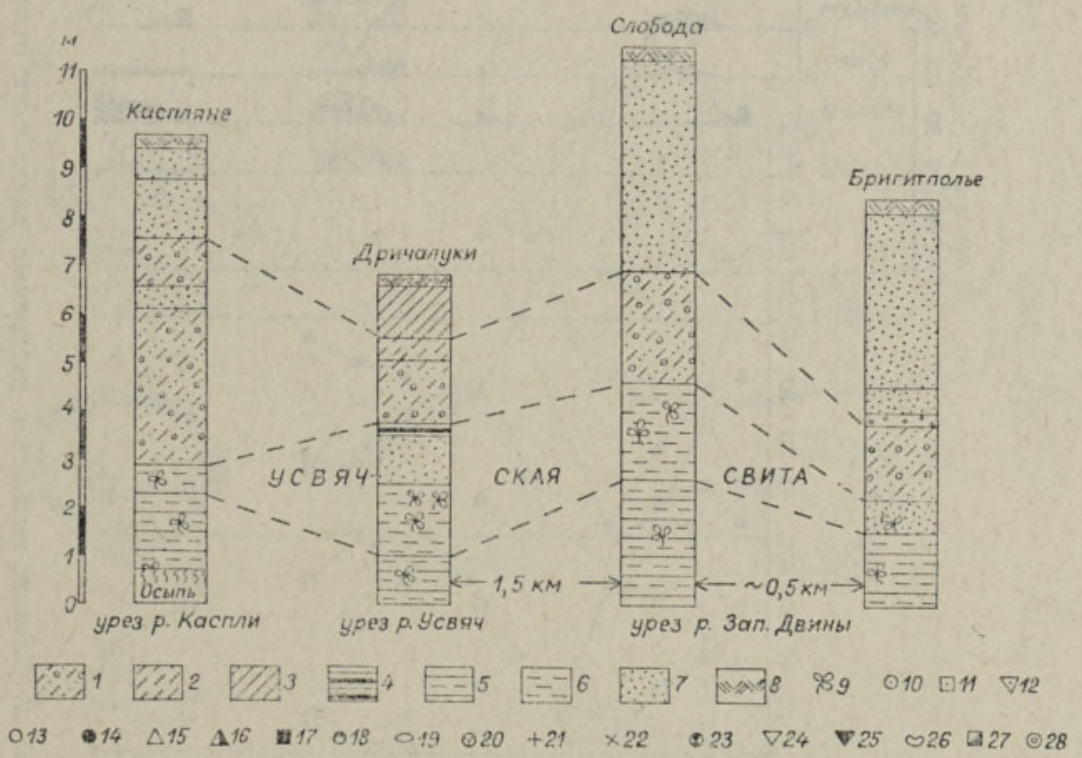

Рис. 1. Сопоставление валдайских отложений изученных разрезов береговых обрывов Западной Двины и ее притоков в окрестности города Сураж. 1 - морена, 2 супесь, 3 - суглинок, 4 - ленточная глина, 5 - темнр-серый алеврит, 6 - желтый алеврит, 7 - песок, 8 - современная почва, 9 - растительные остатки, 10 - пыльца трав (NAP), 11 - древесные породы (AP), 12 - споры, 13 - Betula, 14 Pinus, 15 - Picea, 16 - Abies, 17 - Querc. mixt., 18 - Gramineae, 19 - Cyperaceae, 20 - Ericales, 21 - Artemisia, 22 - Chenopodiaceae, 23 - Varia, $24-$ Bryales, 25.- Sphagnum, 26 - Polypodiaceae, 27 - Lycopodium, 28 - Equisetum. 


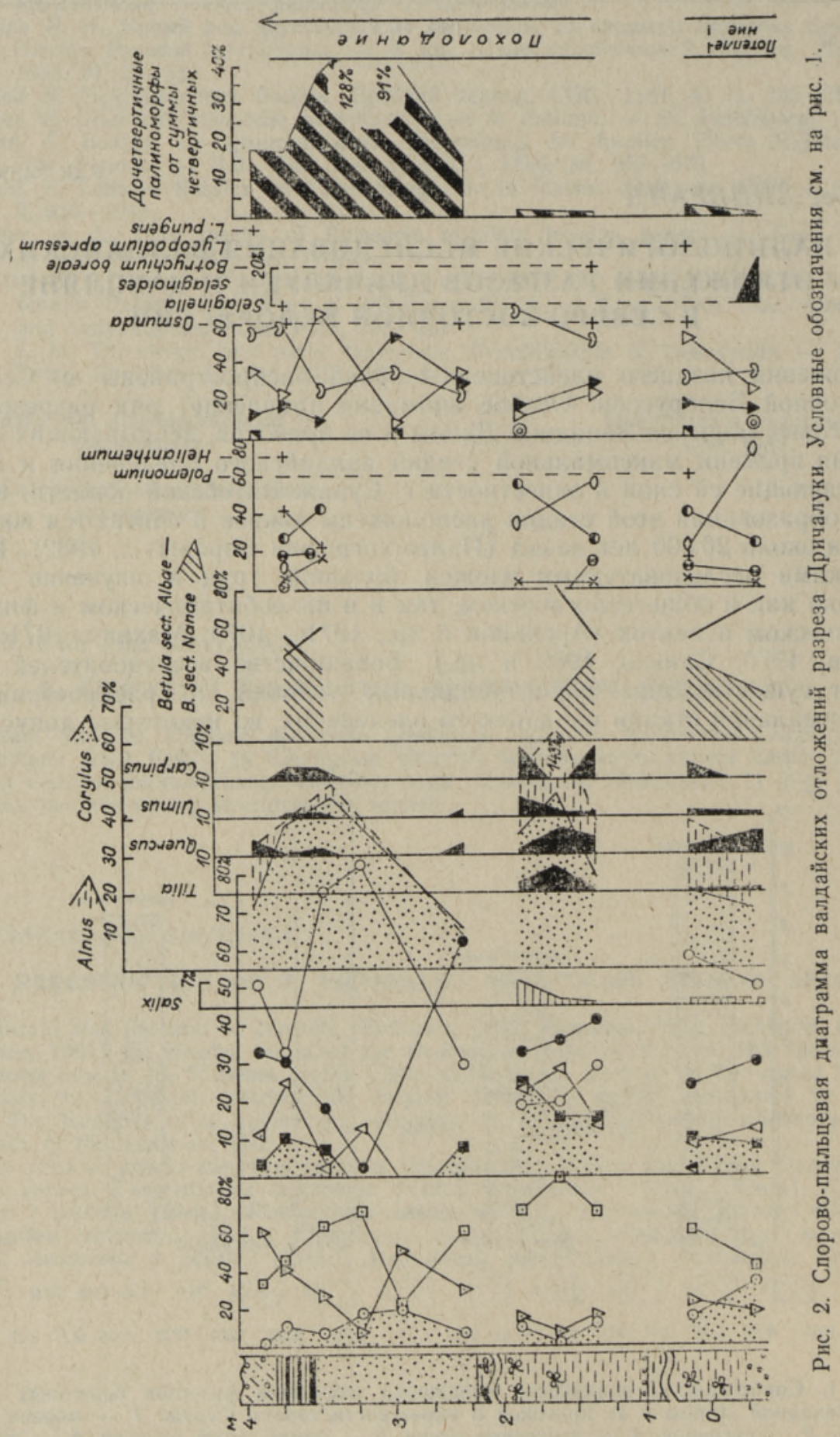




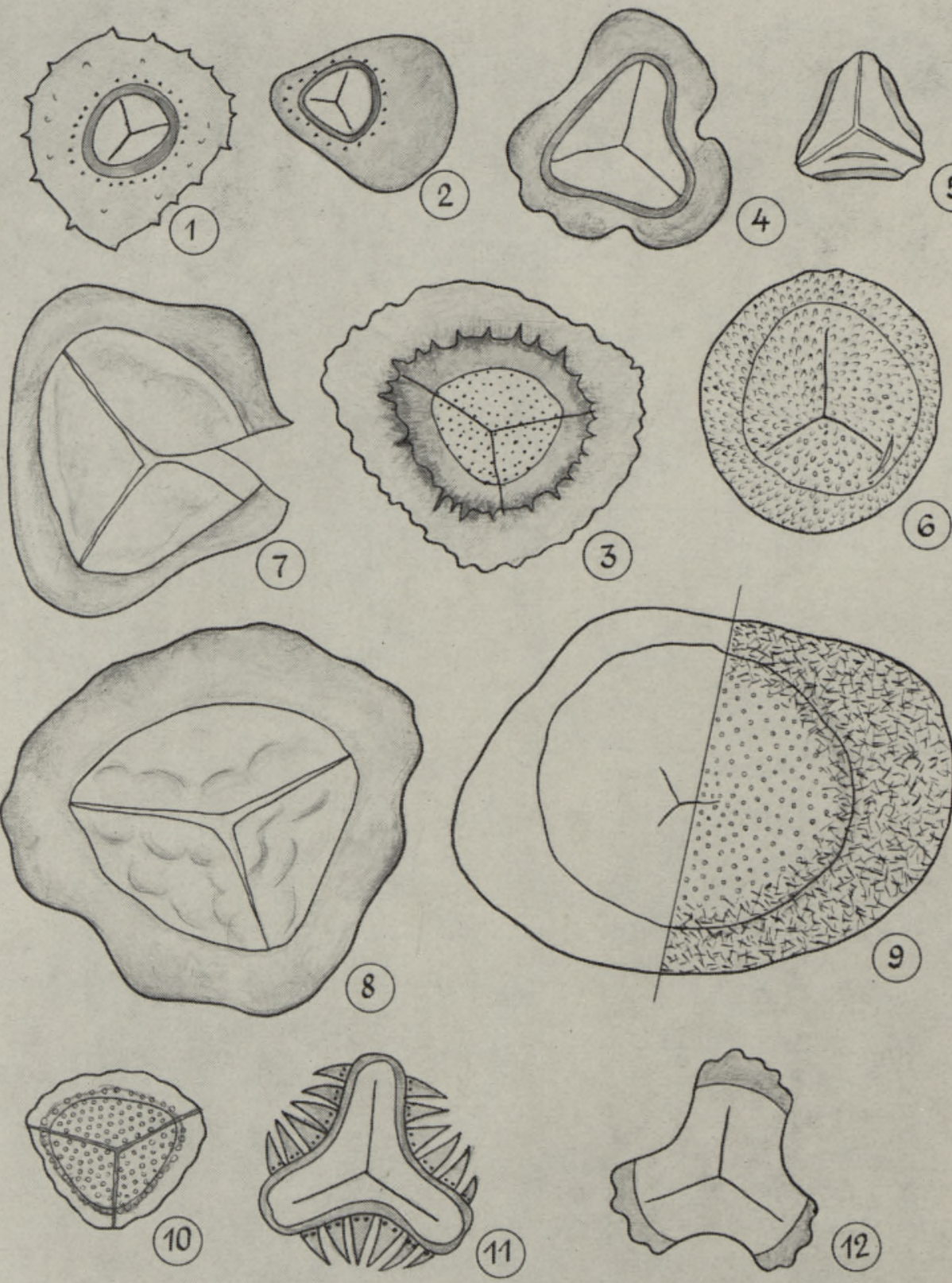

(12)

Рис. 4. Переотложенные дочетвертичные палиноморфы разреза Каспляне. $1-3$ Trematozonotriletes sp. sp., 4 - Simozonotriletes sp., 5 - Gleichenia sp., 6 - Retusotriletes sp., 7-8 - Euryzonotriletes sp. sp., 9-Perisaccus primigenius Naum., 10 Hymenozonotriletes pusillus (Ibr.) Isch., 11 - Diatomozonotriletes sp., 12 - Trilobozonotriletes sp. 
наличие межледниковья (Серебрянный, 1978). Палинологический метод до сих пор нашел скромное применение в этих исследованиях, возможно, из-за большого количества переотложенной пыльцы в этих отложениях. В настоящей статье изложены результаты палинологических исследований двух разрезов (Дричалуки и Каспляне), обсуждены вопросы переотложения и палеогеографическая обстановка.

В ходе полевых работ, руководимых Л. Н. Вознячуком в 1979 г., нам удалось познакомиться с геологическим строением двух вышеуказанных и других не менее интересных разрезов, расположенных неподалеку друг от друга (рис. 1). Обнажение Дричалуки находится в 2,5 км к северу от г. Сураж, на левом берегу р. Усвяч (правый приток Западной Двины), на 100 м выше ее устья. Разрез Слобода вскрывается на правом берегу Западной Двины и разрез Бригитполье на ее левом берегу примерно на 4,0 и 4,5 км севернее г. Сураж. Обнажение Каспляне расположено на правом берегу р. Каспли (левый приток Западной Двины), в 5 км к юго-востоку от г. Сураж. Во всех этих разрезах прослеживается слой коричневой морены с фиолетовым оттенком, который покрывается водноледниковыми желтоватыми песками (Слобода, Каспляне, Бригитполье) или слоем компактного коричневого суглинка (Дричалуки). Под мореной залегает желтоватая песчанистая и алевритистая аллювиально-озерная толща — усвячская свита, - типовой разрез которой находится в обнажении Дричалуки на берегу р. Усвяч (Арсланов и др., 1971б). Здесь усвячская свита нанболее полно представлена и часто включает в себя прослои растительного детрита мощностью до 5 см. Иногда прослои смяты в складки неправильной формы вследствие мерзлотных деформационных процессов. В усвячской свите разреза Каспляне прослеживаются морозобойные трещины. Нижняя пачка, заходящая под урез воды, представлена темно-серыми глинистыми алевритами, а органнческий детрит в них тонкими прослойками или в распыленном виде.

Из-за большого количества растительного детрита наибольшее внимание палеоботаников и исследователей, применяющих метод ${ }^{14} \mathrm{C}$, привлекал разрез Дричалуки. Ф. Ю. Величкевичем (Арсланов и др., 1971б) был определен сложный и смешанный комплекс флоры отложений усвячской свиты, состоящий из шести групп - гипоарктические виды, гелиофиты, водно-болотные растения, флора таежных и смешанных лесов, термофильные и экзотические, неогеновые и девонские виды (последние три считались переотложенными). На основе этого был сделан вывод о крайне суровых климатических условиях времени образования отложений усвячской свиты. Таким образом, прослойки органического детрита в желтоватых алевритах и песках не признак потепления, а результат намыва разновозрастных растительных остатков в перигляциальной зоне.

В результате палинологических исследований усвячской свиты в разрезе Дричалуки нами были обнаружены смешанные споровопыльцевые комплексы, состоящие как из четвертичных, так и из дочетвертичных форм (рис. 2). Қоличество последних, подсчитанное сверх суммы четвертичных, особенно велико в слое песка (до 128\%). Представлены они переотложенными спорами преимущественно из карбоновых (Кедо, 1966), а также девонских и мезойских пород (рис. 3,4$).$ Несмотря на то, что в общем составе четвертичных пыльцы и спор преобладают древесные породы, в том числе до $25 \%$ широколиственных, нет основания говорить о межледниковье. Четвертичные спектры, в свою очередь, смешанные, состоят как из пыльцы деревьев широколиственных лесов, так и из пыльцы тундровых травянисто-кустарниковых растений с карликовыми березами $(20-58 \%)$. Обитание столь различных по экологическим потребностям растений на одной и той 
же территории невозможно. Дальний же снос пыльцы из таких отдаленных друг от друга растительных зон несущественен. Поэтому совместное нахождение пыльцы названных выше растений в отложениях говорит о существенном переотложении. Наряду с инситными пыльцой и спорами перигляциальной растительности в большом количестве погребалась и пыльца древесных пород, переотложенная из микулинских межледниковых отложений. Например, участие переотложенной пыльцы термофильных пород достигает $20-40$, лещины 50 , а ольхн даже $143 \%$. Столь значительное переотложение свойственно холодному времени, особенно в условиях уснления эрозионных процессов. Низкорослая, разреженная и очень скудная перигляциальная растительность, распространившаяся во время накопления желтоватой аллювиальноозерной усвячской толщи перед надвиганием ледника максимальной стадии валдайского оледенения, продуцировала очень мало пыльцы и спор. На фоне незначительного количества последних превалирующей стала именно переотложенная пыльца. Пренебрежение фактом переотложения может привести к неправильной оценке палеогеографической обстановки в качестве межледниковой, тогда как она перигляциальная.

В залегающем ниже темно-сером алеврите разреза Дричалуки количество переотложенных пыльцы и спор как дочетвертичных, так к четвертичных межледниковых пород уменьшается, а количество инситной пыльцы травянистых растений $(37 \%)$, карликовых берез $(25-44 \%)$ и спор Selaginella selaginoides (L.) Link. (22\%) увеличивается. Это говорит о более теплых климатических условиях во время накопления темно-серого алеврита, чем во время образования желтоватых слоев усвячской свиты.

Отложения в разрезе Каспляне больше насыщены пыльцой и спорами, чем в разрезе Дричалуки. Они представлены в основном четвертичными формами, дочетвертичных мало (рис. 5). Эти спектры, также смешанные, состоят из переотложенной пыльцы межледниковых пород и инситных пыльцы и спор перигляциальных растений. Характерно наибольшее количество переотложенной пыльцы термофильных пород, особенно ольхи $(80 \%)$ и лещины $(57 \%)$ в морене и ее постепенное уменьшение вниз по разрезу. Это обусловлено увеличением количества пыльцы перигляциальной растительности в этом же направлении, особенно в темно-сером алеврите. Кроме пыльцы термофильных пород, переотложена и часть пыльцы бореальных растений - сосны, древовидной березы и ели, входящих в состав как межледниковой, так и перигляциальной растительности. Поэтому можно лишь приблизительно ограничить переотложенную и инситную части спектров. По-видимому, значительная часть пыльцы бореальных древесных пород также переотложена. Поэтому пыльца древесных пород в общем составе пыльцы и спор в данном случае не признак облесенности района, как предполагалось ранее при интерпретации палинологических данных. Такое большое количество переотложенной пыльцы в отложениях позволяет предположить, что только редкие деревья древовидной березы, сосны, возможно и ели, участвовали в составе перигляциальной растительности. В составе последней широко распространены травянистые растения $(20-60 \%)$, особенно осоковые и карликовые березы $(24-90 \%)$. Это говорит о холодных и влажных климатических условиях, характерных для времени надвигания ледника.

Из-за большого количества переотложенной пыльцы и малочисленности изученных нами разрезов еще трудно выделить определенные пыльцевые зоны как коррелятивные единицы. Но все же рассматриваются отдельные спорово-пыльцевые комплексы (рис. 5). Особо выделяется интервал 1,6-2,2 м над урезом р. Қаспли. Здесь преобладает 


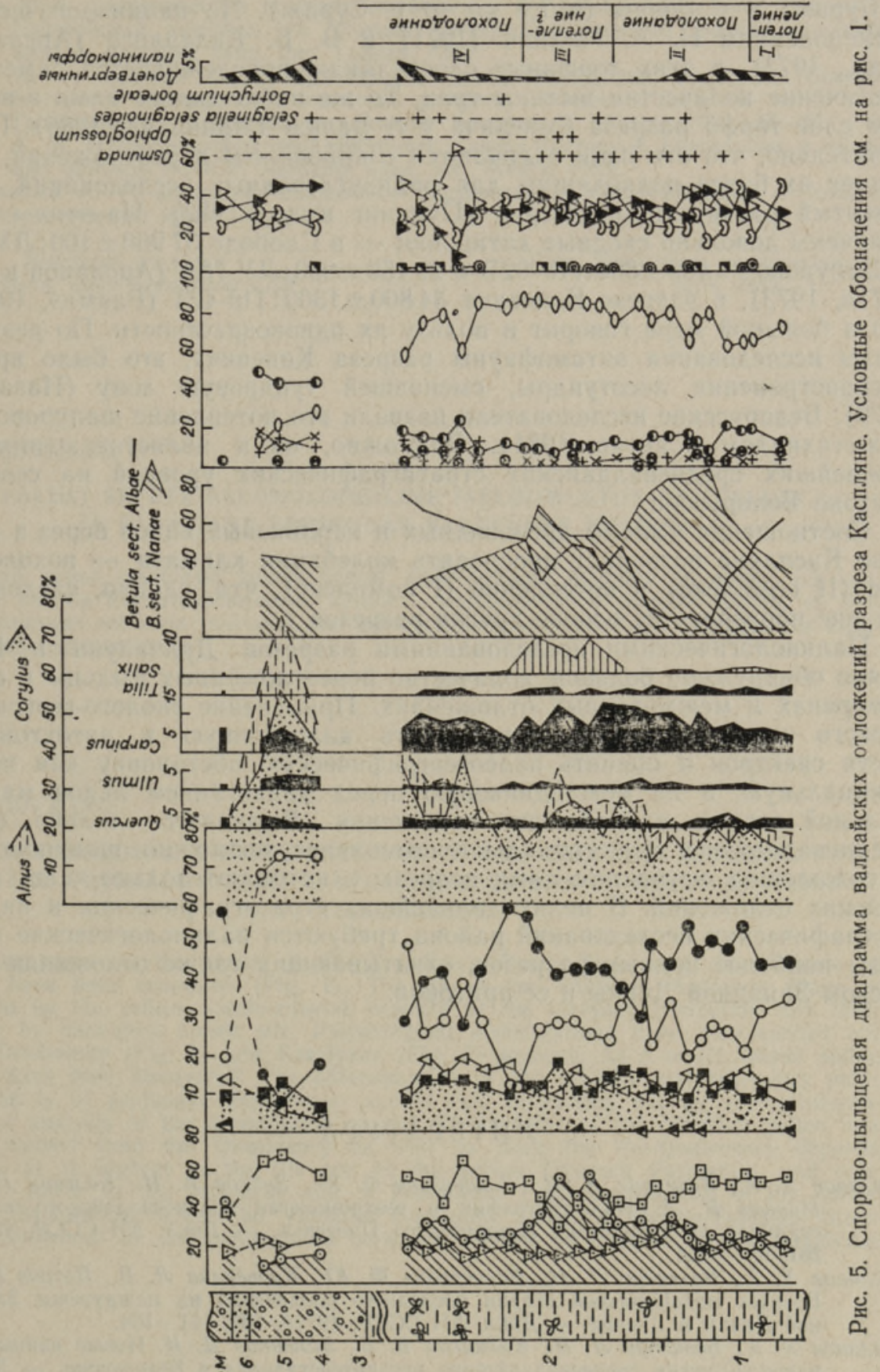


пыльца травянистых растений (до 60\%), пыльцы ивы до 10\% (III комплекс). Әто обусловлено, по-видимому, влиянием местной прибрежной растительности, связанным с более интенсивным торфообразованием на берегах водоемов. Образование прослоек торфа прослеживается в близлежащих разрезах на р. Каспли - Шапурово (на 3,5 км юго-восточнее г. Сураж) и Слободы (в 1,5 км от г. Сураж). По палинологическим исследованиям Н. А. Махнач (1971) и В. Б. Кадацкого (Арсланов и др., 1973), в этих торфяных слоях также прослеживается заметное увеличение количества пыльцы трав. То же наблюдалось нами в верхнем слое торфа разреза Коневича у г. Велиж (Лийвранд, 1985). Примечательно, что эти слои отличаются сокращением переотложения, что делает их более подходящим для радиоуглеродных исследований, чем намытый растительный детрит (Пуннинг и др., 1982). Из этих слоев получены довольно сходные датировки - в Слободе $37960 \pm 100: Л У-98$, в Шапурово $36400 \pm 800:$ ЛУ-92В и $29150 \pm 850:$ ЛУ-78А (Арсланов и др., $1971 a, 1973)$, в разрезе Коневича $34800 \pm 1300: T \ln -424$ (Раямяэ, 1982), что в большой мере говорит в пользу их одновозрастности. По результатам исследования энтомофауны разреза Коневича, это было время распространения лесотундры, сменившей тундровую зону (Назаров, 1979). Белорусские исследователи назвали это потепление шапуровским межстадиалом (Санько, 1981). Возможно, он и является одним из важнейших средневалдайских стратиграфических уровней на северовостоке Белоруссии.

Соотношение пыльцы древовидных и карликовых видов берез в разрезе Каспляне позволяет проследить колебания климата - похолодание (II комплекс) и потепление (I комплекс), что, однако, следовало бы еще проверить на основе других разрезов.

Палинологическими исследованиями разрезов Дричалуки и Каспляне обнаружено большое количество переотложенных пыльцы и спор в моренах и межморенных отложениях. Применение эколого-географического анализа позволило различить аллохтонную и автохтонную части спектров и оценить палеогеографическую обстановку как периглящиальную, а не межледниковую перед надвиганием льдов максимальной стадии валдайского оледенения. Выделяется только одно средневалдайское межстадиальное потепление, возможно, шапуровское. К сожалению, изученные нами разрезы охватывают только часть валдайских отложений. В целях дальнейших стратиграфических и палеогеографических исследований района требуются палинологические анализы наиболее полных разрезов, охватывающих также отложения под урезом Западной Двины и ее притоков.

\section{ЛИТЕРА Т У Р А}

Арсланов Х. А., Вознячук Л. Н., Величкевич Ф. Ю., Зубков А. И., Калечиц Е. Г., Махнач H. А. Палеогеография и геохронология средневалдайского интерстадиала на территорин Белорусского Поозерья. - Докл. АН СССР, 1971a, 201, 661-664.

Арсланов Х. А., Вознячук Л. Н., Величкевич Ф. Ю., Курьерова Л. В., Петров Г. С. Возраст максимальной стадии последнего оледенения на междуречье Западной Двины и Днепра. - Докл. АН СССР, 19716, 196, 161-164.

Арсланов Х. А., Возняиук Л. Н., Кадацкий В. Б., Зименков Д. Н. Новые данные по палеогеографин средневалдайского мегаинтерстадиала в Белоруссии. - Докл. AH CCCP, 1973, 213, 901-903.

Кедо $Г$. Н. Споры нижнего карбона Припятского прогиба. - В кн.: Палеонтология БССР. Мннск, 1966, 3-143.

Лийвранд $Э$. К методике палинологических исследований отложений межледниковых и ледниковых эпох на примере разреза Коневича в Смоленской области, Изв. АН ЭССР. Геол., 1985, 34, 18-21. 
Махнач $H$. A. Эิтапы развйтия расстительности Белоруссии в антропогене. Минск, 1971.

Назаров В. И. Антропогеновые насекомые северо-востока Белоруссии и сопредельных районов. Автореф. канд. дис. М., 1979.

Палеогеография Европы за последние сто тысяч лет. Атлас-монография. М., 1982.

Пуннине Я.-М., Раямяэ Р., Хютт Г. О возрасте озерно-аллювиальных отложений в разрезах Дричалуки и Бригитполе (Северная Белоруссия). - Изв. АН ЭССР. Геол., 1982, 31, 15-20.

Раямяэ P. A. Геохронология позднего плейстоцена северо-западной части ВосточноЕвропейской равнины, по данным усовершенствованного радноуглеродного метода. Автореф. канд. дис. Таллин, 1982.

Санько $A . \Phi$. Краткий очерк стратиграфин неоплейстоценовых отложений СевероВосточной Белоруссии и смежных районов Смоленской области. - В кн.: Геологические исследования кайнозоя Белоруссии. Минск, 1981, 45-55.

Санько А. Ф. Палеогеография неоплейстоцена Северо-Восточной Белоруссии и смежных районов РСФСР. Автореф. канд. дис. Минск, 1982.

Серебрянный Л. Р. Динамнка покровного оледенения и гляциоэвстазия в позднечетвертичное время. М., 1978.
Ннститут геологии
Академии наук Эстонской ССР
Поступила в редакцию
$6 / \mathrm{IX} 1983$

\section{Elsbet LIIVRAND}

\section{VALDAI SETETE PALUNOLOOGILINE ISELOOMUSTUS DRITSALUKI JA KASPLJANE LEIUKOHAS VALGEVENE KIRDEOSAS}

Uuritavad setted sisaldasid suurel hulgal ümbersettinud ōietolmu ja eoseid nii kvaternaari kui ka kvaternaarieelsetest kihtidest. Palünoloogiline analüüs näitab, et Valdai maksimumi eel levis uuritaval alal periglatsiaalne taimkate. On jälgitav üks interstadiaalne soojenemine.

\section{PALYNOLOGICAL INVESTIGATIONS OF THE VALDAIAN DEPOSITS IN THE DRICHALUKY AND KASPLYANE SECTIONS OF NORTH-EASTERN BYELORUSSIA}

Some sequences on the banks of the Zapadnaya Dvina River and its affluents at Surazh have been examined (Fig. 1). The till of the Valdaian Maximum Stage is underlain by the yellow limnic-alluvial deposits of the Uzvyach Formation and they, in turn, by dark-grey limnic silt. Palynological investigations have been carried out in the Drichaluky (Fig. 2) and Kasplyane (Fig. 5) sections. As a result, mixed pollen spectra have been discovered. The differentiation of the primary and secondary palynomorphs is of particular importance, and it can be carried out by ecological-geographical analysis of the investigated species. The content of the rebedded pollen and spores derived from the Quaternary as well as from the Pre-Quaternary deposits (Fig. 3, 4) is highest in the till and in the yellow Uzvyach Formation, and considerably lower in the dark-gray silt. A Periglacial vegetation spread in the northeast of Byelorussia before the Valdaian Maximum Stage. A Middle-Valdaian Interstadial, evidenced by the maximum of herbs and willow, is traceable in the Kasplyane section. 